\title{
Spatio-Temporal Dynamics of Environmental Status Based on a Remote Sensing Ecological Distance Index (RSEDI) in the Oases of Hexi Corridor in Northwest China
}

\author{
Kunming Guo ${ }^{1}$, Jintao Zhao ${ }^{2}$, Xiaoyun Wang ${ }^{1,3}$, Yaowen Xie ${ }^{1,3 *}$ \\ ${ }^{1}$ College of Earth and Environmental Sciences, Lanzhou University, Lanzhou, China \\ ${ }^{2}$ College of Resources and Environmental Science, Ningxia University, Yinchuan, China \\ ${ }^{3}$ The Key Laboratory of Western China's Environmental Systems, Ministry of Education (MOE), \\ Lanzhou, China
}

Received: 7 November 2020

Accepted: 25 January 2021

\begin{abstract}
The Hexi Corridor is a typical ecologically fragile and sensitive area, and the oases areas in the middle are the core area of the economic development of the Hexi Corridor, where the ecological problems are most serious. It is of great significance for regional ecological environment construction and sustainable development to clarify the ecological environment status and its change distribution of the Hexi oases areas. This study used remote sensing ecological distance index (RSEDI) model to generate time series of various environmental indexes of the Hexi oases areas from 1986 to 2020, based on Landsat TM/OLI images. And the changes of ecological environment were quantitatively analyzed by employing the coefficient of variation, Theil-Sen median trend analysis and the Mann-Kendall test, and Hurst index method. Results showed that: (1) The mean value of RSEDI of Hexi oases showed an increasing trend, increasing from 0.386 in 1986 to 0.405 in 2020. (2) The ecological environment changes of the Hexi oases were relatively stable, areas with low coefficients of variation accounted for $62.70 \%$. (3) The ecological improvement areas (26.53\%) were smaller than the ecological decline areas (30.83\%), and areas with no change accounted for $42.62 \%$. (4) $75.14 \%$ of areas were persistent, showing the ecological environment changes had strong sustainability. The areas with persistence and improvement accounted for $20.72 \%$, which were distributed throughout the study area, mostly around the periphery of artificial oasis such as Shandan, and Yongchang. The areas with persistence and degradation accounted for $21.55 \%$, which were concentrated in the middle of the study area, mainly
\end{abstract}

*e-mail: xieyw@1zu.edu.cn 
in Sunan and Gaotai. In short, the ecological environment of the Hexi oases had been improved, but it also faced huge challenges.

Keywords: ecological environment, RSEDI, variation coefficient, trend analysis method, Hurst index, Hexi oases

\section{Introduction}

Changes of ecological environment in arid and semi-arid regions are directly related to the sustainable development of human society [1], where precipitation is scarce, evaporation is huge, water resources are extremely scarce, and soil erosion, land desertification, salinization and other ecological problems are serious. The ecological environment here is extremely fragile, and its ability to resist external interference is very poor, where small-scale disturbances by humans or nature can cause major changes, and it has become a key area of global environmental change research [2-3]. Oasis, a unique geographical landscape in arid regions, is the environmental foundation that sustains human production and life in arid regions [4-5]. Oases in China are concentrated in desert areas west of Helan Mountain and north of the Qinghai-Tibet Plateau. Their areas only account for $4 \% \sim 5 \%$ of the total area of arid and semiarid regions, but more than $90 \%$ of the population and more than $95 \%$ of the social wealth are concentrated here [6].

The Hexi Corridor lying on the east side of the desert area in northwestern China is located at the intersection of the arid-semi-arid area and the Qinghai-Tibet alpine area in the three natural areas of China, forming a typical landscape pattern of "mountain-oasis-desert" [7-8], which is one of the regions in China where the ecosystem is quite fragile. With the development of the oases of Hexi Corridor, the scale and landscape pattern of the oases had undergone tremendous changes, and the spatial and temporal distribution of water resources had changed. The wetlands had shrunk, natural vegetation had decreased, and land desertification and salinization had become more and more serious [9-12]. Understanding the ecological environment of the Hexi oases is of great significance to regional ecological environment construction and sustainable development.

Remote sensing technology is widespread used in the field of ecological environment due to its long time, wide range, and rich information [13-14], and it has become an effective method for monitoring regional soil, vegetation, and water bodies [15-16]. In addition, many methods such as wavelet analysis [17], change vector analysis [18-19], Theil-Sen median trend analysis and Mann-Kendall test [20-21], and Hurst exponent method [22] have been widely used in the analysis of long time series data. At present, a single environmental indicator is widely used for regional ecological environment monitoring and assessment, such as using vegetation index to monitor forest ecosystem [23], extracting water body index for water environment assessment [24], and using surface temperature to evaluate urban heat island effect [25], and so on. The ecological environment is affected by many factors, and a single environmental factor cannot objectively and comprehensively reflect its ecological environment changes. Therefore, it is particularly important to integrate multiple environmental factors to evaluate regional ecological environment.

Evaluation methods that integrate multiple environmental factors can be divided into two categories: One is a multi-index evaluation model based entirely on remote sensing data. For example, Xu [26] constructed a remote sensing based ecological index (RSEI) using the normalized difference vegetation index (NDVI), wetness component of the tasseled cap transformation (Wet), normalized difference built-up and soil index (NDBSI), and land surface temperature (LST) extracted by remote sensing to analyze the ecological environment changes in Fujian. Rhee et al. [27] proposed a scaled drought condition index (SDCI) combining LST, NDVI, and precipitation data from Tropical Rainfall Measuring Mission (TRMM) satellite, for monitoring agricultural drought conditions in both arid and humid regions. The other is a comprehensive index evaluation model which combines remote sensing data with other types of data. For instance, Alejandra et al. [28] assessed the urban environmental quality index (UEQI) of Cali, Colombia, integrating remote sensing and census data by using the multivariate statistical analysis. Li et al. [29] used the China's first geographic census data, high resolution images and terrain data to evaluate the ecological environment status of Guangxi in 2015.

In the comprehensive index evaluation method established by combining remote sensing data and other types of data, the survey statistical data is not easy to obtain, and the index weight setting is affected by human factors, which has relatively large limitations. The evaluation method based entirely on remote sensing data has the advantages of objectivity, multiple indicators and high practicability, and can monitor and evaluate the regional ecological environment rapidly. This study aims to use remote sensing ecological distance index (RSEDI) combining NDVI, wetness index (WI), Albedo, salinization index (SI), index-based built-up index (IBI) and LST to evaluate the ecological environmental status of the Hexi oases. The time series of different indices will be generated, and then employ the coefficient of variation, Theil-Sen median trend analysis and Mann-Kendall test, and Hurst index method to comprehensively analyze the changes of the ecological environment quality, with a view 
to providing a scientific reference for the ecological environmental protection and governance as well as sustainable development of this region.

\section{Materials}

\section{The Study Area}

The Hexi Corridor $\left(37^{\circ} 17^{\prime} \sim 42^{\circ} 48^{\prime} \mathrm{N}, 9^{\circ} 18^{\prime} \sim 104^{\circ} 14^{\prime} \mathrm{E}\right)$, located in the northwest of Gansu Province, is surrounded by the Wushaoling Mountains to the east, Xinjiang Uygur Autonomous Region to the west, Qinghai to the south, and Inner Mongolia Autonomous Region to the north. It is a narrow and long corridor with a northwest-southeast direction [30], governing five prefecture-level cities: Wuwei, Jinchang, Zhangye, Jiuquan, and Jiayuguan. The terrain is high in the south and low in the north: the Qilian Mountains in the south are rich in water resources and are the birthplace of the three inland rivers of the Hexi Corridor; the central plain area is moistened by the three inland rivers, and three major oases areas have been developed: Shiyang River oases, Heihe oases and Shule River oases, which are the main water consumption areas; and the mountainous areas in the north with low altitudes are mostly composed of low-lying hills.

The Hexi Corridor, located in the hinterland of the Eurasian continent has a continental arid climate, with sparse precipitation, heavy wind and sand. The average annual temperature is $5.8 \sim 9.3^{\circ} \mathrm{C}$, and the annual precipitation is mostly below $200 \mathrm{~mm}$ [31]. The difference in water and heat of this area is obvious: the annual average temperature, sunshine hours, precipitation variability and dryness gradually increase from east to west, while the annual precipitation and relative humidity gradually decrease [32]. Although the Hexi Corridor has sparse rainfall, it has long sunshine hours, which is conducive to the growth of crops. It is an important production place for grains and fruits, and is known as the "Northwest Granary". In addition, the rich iron and nickel mineral resources in the area also provide good conditions for its industrial development [32].

The study area is the oases areas in the middle of the Hexi Corridor (Fig. 1), which is the core area of the economic development of the Hexi Corridor and also the most densely populated area in the Hexi Corridor, with the highest water resources development and utilization and the most serious environmental problems. Changes of ecological environment of the Hexi oases are directly related to the ecological security of Gansu Province and even the entire northwest region.

\section{Data Sources}

Eight time periods (1986, 1990, 1995, 2000, 2005, 2010, 2015, and 2020) of remote-sensing images from Landsat TM/OLI were selected to monitor the changes of environment. They were provided by the United States Geological Survey (https://earthexplorer.usgs.gov/), the Geospatial Data Cloud (http://www.gscloud.cn/), and the Institute of Remote Sensing and Digital Earth, Chinese Academy of Sciences (http://www.radi.cas.cn/).

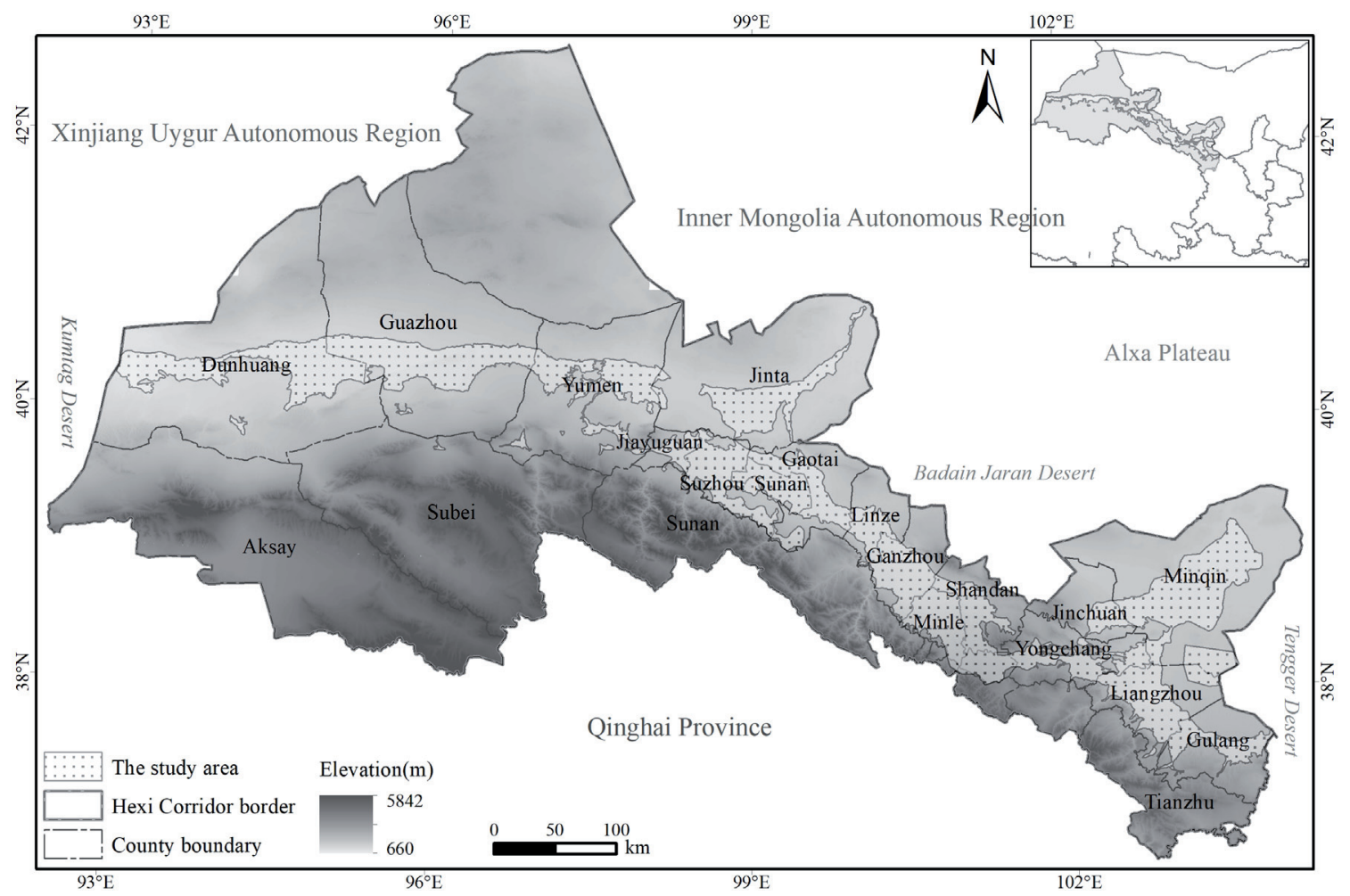

Fig. 1. Location of the study area. 
In order to make it comparable between different periods, we selected 11 Landsat images during the vegetation flourishing season of each period (Table 1), which covered the whole study area. The cloud coverage of all images was less than $10 \%$, and the quality was good, which could meet the needs of this assessment. These images had undergone preprocessing such as radiation calibration, atmospheric correction, geometric correction, image mosaic and cropping, and then used for subsequent calculations.

\section{Methods}

\section{Environmental Assessment Indicators}

Vegetation is extremely sensitive to the changes of regional ecological environment [33], and its distribution and dynamic changes are of great significance for maintaining ecological stability in arid regions. Among all kinds of vegetation indices, normalized differential vegetation index (NDVI) is the most widespread used vegetation index [15, 34-35]. Besides, the wetness, greenness, and brightness components after tassel cap transformation have been widely used in ecological environment quality evaluation [36-38]. In particular, the wetness component is used as the wetness index (WI) indicator as it can be used to monitor soil degradation.

Land degradation in arid areas is mainly manifested in two forms, namely desertification and salinization.
Affected by the interference of human activities, such as grazing, unreasonable using of water resources, the environmental conditions of the Hexi oases are very fragile [39] and the land is easily degraded [40]. Land degradation, namely desertification and salinization, not only limits agricultural development in arid regions, but also poses a significant risk to ecological environment and biosphere, which is one of the major environmental problems faced by arid and semi-arid regions [41-42]. Zeng et al. [43] proposed the concept of Albedo-NDVI feature space and found that the albedo can reflect the desertification degree. Khan et al. [44] declared that the salinity index (SI) can be well used to invert soil salinity in arid areas.

Studies have shown that urban expansion will affect regional water, soil, atmosphere and biodiversity and other environmental factors [45]. The increase of buildings during the urbanization process can lead to the drying of land surface, which will have a negative effect on the urban environment [25]. The index-based built-up index (IBI) has been widely used to characterize built land [46]. Additionally, the land surface temperature (LST) is closely related to the growth and distribution of vegetation and the evaporation cycle of surface water resources [21]. It has been widespread used in climate change, surface energy balance and dynamic monitoring of environmental quality [47-48]. The technology of retrieving LST based on remote sensing is becoming more and more mature [49-52]. In this paper, the LST has been retrieved based

Table 1. Landsat images used in this study.

\begin{tabular}{|c|c|c|c|c|c|c|c|c|}
\hline Path/Row & 1986 & 1990 & 1995 & 2000 & 2005 & 2010 & 2015 & 2020 \\
\hline $131 / 33$ & $\begin{array}{c}16 \text { Jun } \\
1988\end{array}$ & $\begin{array}{c}25 \text { Jun } \\
1991\end{array}$ & $\begin{array}{l}6 \mathrm{Jul} \\
1995\end{array}$ & $\begin{array}{l}19 \mathrm{Jul} \\
2000\end{array}$ & $\begin{array}{l}2 \text { Aug } \\
2005\end{array}$ & $\begin{array}{l}15 \mathrm{Jul} \\
2010\end{array}$ & $\begin{array}{c}14 \mathrm{Aug} \\
2015\end{array}$ & $26 \mathrm{Jul} 2020$ \\
\hline $131 / 34$ & $\begin{array}{l}16 \text { Jun } \\
1988\end{array}$ & $\begin{array}{c}25 \text { Jun } \\
1991\end{array}$ & $\begin{array}{l}6 \mathrm{Jul} \\
1995\end{array}$ & $\begin{array}{l}19 \mathrm{Jul} \\
2000\end{array}$ & $\begin{array}{l}5 \text { Aug } \\
2006\end{array}$ & $\begin{array}{c}13 \mathrm{Aug} \\
2009\end{array}$ & $\begin{array}{c}14 \text { Aug } \\
2015\end{array}$ & $\begin{array}{c}26 \text { Sept } \\
2019\end{array}$ \\
\hline $132 / 33$ & $\begin{array}{l}\text { 9 Sept } \\
1987\end{array}$ & $\begin{array}{c}16 \text { Jun } \\
1991\end{array}$ & $\begin{array}{c}11 \text { Jun } \\
1995\end{array}$ & $\begin{array}{c}11 \mathrm{Aug} \\
2000\end{array}$ & $\begin{array}{c}24 \mathrm{Jul} \\
2005\end{array}$ & $\begin{array}{c}22 \mathrm{Jul} \\
2010\end{array}$ & $\begin{array}{l}6 \text { Sept } \\
2015\end{array}$ & $\begin{array}{c}18 \text { Aug } \\
2020\end{array}$ \\
\hline $132 / 34$ & $\begin{array}{c}9 \text { Sept } \\
1987\end{array}$ & $\begin{array}{c}20 \text { Jun } \\
1990\end{array}$ & $\begin{array}{c}\text { 11 Jun } \\
1995\end{array}$ & $\begin{array}{c}18 \mathrm{Aug} \\
2000\end{array}$ & $\begin{array}{l}7 \text { Jun } \\
2005\end{array}$ & $\begin{array}{c}8 \text { Sept } \\
2010\end{array}$ & $\begin{array}{c}17 \mathrm{Jul} \\
2014\end{array}$ & 1 Sept 2019 \\
\hline $133 / 33$ & $\begin{array}{c}15 \text { Aug } \\
1987\end{array}$ & $\begin{array}{c}20 \text { Jun } \\
1990\end{array}$ & $\begin{array}{c}21 \text { Aug } \\
1995\end{array}$ & $\begin{array}{c}18 \mathrm{Aug} \\
2000\end{array}$ & $\begin{array}{l}15 \mathrm{Jul} \\
2005\end{array}$ & $\begin{array}{c}14 \mathrm{Aug} \\
2010\end{array}$ & $\begin{array}{l}13 \mathrm{Sept} \\
2015\end{array}$ & $\begin{array}{c}24 \text { Sept } \\
2019\end{array}$ \\
\hline $134 / 32$ & $\begin{array}{c}18 \mathrm{Jul} \\
1986\end{array}$ & $\begin{array}{c}30 \text { Aug } \\
1990\end{array}$ & $\begin{array}{l}8 \mathrm{Jul} \\
1994\end{array}$ & $\begin{array}{l}8 \mathrm{Jul} \\
2000\end{array}$ & $\begin{array}{c}22 \mathrm{Jul} \\
2005\end{array}$ & $\begin{array}{l}5 \text { Aug } \\
2010\end{array}$ & $\begin{array}{l}18 \mathrm{Jul} \\
2015\end{array}$ & $31 \mathrm{Jul} 2020$ \\
\hline $134 / 33$ & $\begin{array}{l}9 \text { Oct } \\
1987\end{array}$ & $\begin{array}{c}30 \text { Aug } \\
1990\end{array}$ & $\begin{array}{l}8 \mathrm{Jul} \\
1994\end{array}$ & $\begin{array}{c}24 \mathrm{Jul} \\
2000\end{array}$ & $\begin{array}{l}8 \text { Sept } \\
2005\end{array}$ & $\begin{array}{l}5 \text { Aug } \\
2010\end{array}$ & $\begin{array}{l}\text { 4 Jul } \\
2016\end{array}$ & 29 Jul 2019 \\
\hline $135 / 32$ & $\begin{array}{c}25 \mathrm{Jul} \\
1986\end{array}$ & $\begin{array}{c}21 \mathrm{Aug} \\
1990\end{array}$ & $\begin{array}{c}19 \text { Aug } \\
1995\end{array}$ & $\begin{array}{l}1 \mathrm{Jul} \\
2000\end{array}$ & $\begin{array}{l}13 \mathrm{Jul} \\
2005\end{array}$ & $\begin{array}{l}9 \text { Jun } \\
2010\end{array}$ & $\begin{array}{l}9 \mathrm{Jul} \\
2015\end{array}$ & 4 Jun 2020 \\
\hline $136 / 32$ & $\begin{array}{c}30 \text { Jun } \\
1986\end{array}$ & $\begin{array}{c}16 \mathrm{Sept} \\
1991\end{array}$ & $\begin{array}{c}23 \mathrm{Aug} \\
1994\end{array}$ & $\begin{array}{l}31 \text { Aug } \\
2000\end{array}$ & $\begin{array}{l}5 \text { Aug } \\
2005\end{array}$ & $\begin{array}{c}\text { 16 Jun } \\
2010\end{array}$ & $\begin{array}{l}17 \text { Aug } \\
2015\end{array}$ & $\begin{array}{c}30 \text { Aug } \\
2020\end{array}$ \\
\hline $137 / 32$ & $\begin{array}{c}23 \mathrm{Jul} \\
1986\end{array}$ & $\begin{array}{c}19 \text { Aug } \\
1990\end{array}$ & $\begin{array}{c}17 \text { Aug } \\
1995\end{array}$ & $\begin{array}{l}13 \mathrm{Jul} \\
2000\end{array}$ & $\begin{array}{l}9 \text { Jun } \\
2005\end{array}$ & $\begin{array}{c}25 \mathrm{Jul} \\
2010\end{array}$ & $\begin{array}{l}8 \text { Aug } \\
2015\end{array}$ & 2 Jun 2020 \\
\hline $138 / 32$ & $\begin{array}{c}19 \text { Aug } \\
1986\end{array}$ & $\begin{array}{c}14 \text { Sept } \\
1990\end{array}$ & $\begin{array}{c}20 \mathrm{Jul} \\
1995\end{array}$ & $\begin{array}{l}6 \text { Sept } \\
2000\end{array}$ & $\begin{array}{c}22 \mathrm{Aug} \\
2005\end{array}$ & $\begin{array}{c}14 \text { Jun } \\
2010\end{array}$ & $\begin{array}{c}23 \mathrm{Jul} \\
2015\end{array}$ & $\begin{array}{c}12 \mathrm{Aug} \\
2020\end{array}$ \\
\hline
\end{tabular}


Table 2. The calculation formulas of the five indexes.

\begin{tabular}{|c|c|}
\hline Index & Formula \\
\hline NDVI & $\left(\rho_{\text {NIR }}-\rho_{R}\right) /\left(\rho_{\text {NIR }}+\rho_{R}\right)$ \\
\hline WI $_{\text {TM }}$ & $0.0315 \rho_{\mathrm{B}}+0.2021 \rho_{\mathrm{G}}+0.3102 \rho_{\mathrm{R}}+0.1594 \rho_{\mathrm{NIR}}-0.6806 \rho_{\mathrm{SWIR} 1}-0.6109 \rho_{\mathrm{SWIR} 2}$ \\
\hline $\mathrm{WI}_{\mathrm{OLI}}$ & $0.1511 \rho_{\mathrm{B}}+0.1973 \rho_{\mathrm{G}}+0.3283 \rho_{\mathrm{R}}+0.3407 \rho_{\mathrm{NIR}}-0.7117 \rho_{\mathrm{SWIR} 1}-0.4559 \rho_{\mathrm{SWIR} 2}$ \\
\hline Albedo & $0.356 \rho_{\mathrm{B}}+0.130 \rho_{\mathrm{R}}+0.373 \rho_{\mathrm{NIR}}+0.085 \rho_{\mathrm{SWIR} 1}+0.072 \rho_{\mathrm{SWIR} 2}-0.0018$ \\
\hline SI & $\sqrt{\rho_{\mathrm{B}} \times \rho_{\mathrm{R}}}$ \\
\hline IBI & $\frac{2 \rho_{\mathrm{SWIR} 1} /\left(\rho_{\mathrm{SWIR} 1}+\rho_{\mathrm{NIR}}\right)-\left[\rho_{\mathrm{NIR}} /\left(\rho_{\mathrm{NIR}}+\rho_{\mathrm{R}}\right)+\rho_{\mathrm{G}} /\left(\rho_{\mathrm{G}}+\rho_{\mathrm{SWIR} 1}\right)\right]}{2 \rho_{\mathrm{SWIR} 1} /\left(\rho_{\mathrm{SWIR} 1}+\rho_{\mathrm{NIR}}\right)+\left[\rho_{\mathrm{NIR}} /\left(\rho_{\mathrm{NIR}}+\rho_{\mathrm{R}}\right)+\rho_{\mathrm{G}} /\left(\rho_{\mathrm{G}}+\rho_{\mathrm{SWIR} 1}\right)\right]}$ \\
\hline
\end{tabular}

...where $\rho_{\mathrm{NIR}}, \rho_{\mathrm{R}}, \rho_{\mathrm{B}}, \rho_{\mathrm{G}}, \rho_{\mathrm{SWIR}_{1}}$ and $\rho_{\mathrm{SWIR}}$ corresponding to the reflectance of the near-infrared, red, blue, green, short wave infrared 1 (SWIR1) and short wave infrared 2 (SWIR2) bands of TM and OLI images, respectively.

on the band 6 of Landsat TM and band 10 of Landsat OLI/TIRS.

In summary, the formulas of NDVI, WI, Albedo, SI, and IBI are shown in Table 2, and the calculation of LST is based on these references [52-53].

In order to eliminate the difference due to dimension, the six indicators are normalized and converted to dimensionless data, and make their values between $(0,1)$. The formula is shown as:

$$
N I_{i}=\left(I_{i}-I_{\min }\right) /\left(I_{\max }-I_{\min }\right)
$$

...where $N I_{i}$ is the normalized pixel value of index $i$; $I_{i}$ is the original value of the pixel of index $i ; I_{\max }$ and $I_{\min }$ are the maximum and minimum values of index $i$, respectively.

\section{Integration of the Indicators}

Remote sensing ecological distance index (RSEDI) is a method for calculating the comprehensive index based on the theory of Euclidean distance, its applicability in ecological environment monitoring in arid areas has also been confirmed [54-55]. RSEDI can better avoid the shortcomings of the traditional subjective method of index weighting [55]. It takes the minimum value of NDVI and WI, and the maximum value of Albedo, IBI, SI and LST as the points with the worst ecological environment quality in the space, and then calculates the distance from other points to the worst point in the space to represent RSEDI. The greater the distance, the better the quality of the ecological environment; otherwise, the quality of the ecological environment is worse [33]. The calculation formula is shown as:

$R S E D I=\sqrt{\begin{array}{c}\left(N D V I_{i}-N D V I_{\text {min }}\right)^{2}+\left(W I_{i}-W I_{\text {min }}\right)^{2}+\left(\text { Albedo }_{\text {max }}-\text { Albedo }_{i}\right)^{2}+ \\ \left(I B I_{\max }-I B I_{i}\right)^{2}+\left(S I_{\max }-S I_{i}\right)^{2}+\left(L S T_{\max }-L S T_{i}\right)^{2}\end{array}}$

...where $N D V I_{i}, W I_{i}, A$ lbedo $, I B I_{i}, S I_{i}$, and $L S T_{i}$, are the values of NDVI, WI, Albedo, IBI, SI and LST for each pixel; $N D V I_{\text {min }}$ and $W I_{\text {min }}$ are the minimum values of
NDVI and WI; Albedo $\max _{\text {ax }}, I B I_{\max }, S I_{\max }$ and $L S T_{\max }$ are the maximum value of Albedo, IBI, SI and LST.

In order to ensure the comparability of the results in different periods, RSEDI was normalized to $(0,1)$ according to Formula 1 with a $99 \%$ confidence interval. On this basis, combined with the actual situation of the study area, it was further categorised into five levels: Level 1 (0.00-0.10): very poor; Level 2 (0.10$0.35)$ : poor; Level 3 (0.35-0.60): acceptable; Level 4 (0.60-0.90): good; and Level 5 (0.90-1.00): very good.

\section{Monitoring Environmental Changes}

\section{Image Difference}

To understand the change attribute of ecological environment, a simple image differencing method [56] was used based on graded RSEDI images with the formula:

$$
\triangle R S E D I=R S E D I_{b}-R S E D I_{a}
$$

...where $R S E D I_{b}$ and $R S E D I_{a}$ are the RSEDI values of the end year and start year of a time period separately. The positive values indicate that the quality of the ecological environment has been improved, while the negative values indicate that it has been destroyed.

\section{Coefficient of Variation}

The coefficient of variation (CV) can effectively reveal vegetation changes [57-58] and reflect the discrete degree and volatility of time series data [59]. It is calculated by:

$$
C V=\sigma / \mu
$$

...where CV is the coefficient of variation of the RSEDI; $\sigma$ represents the standard deviation of the RSEDI time series; $\mu$ is the mean of RSEDI. The larger CV means the greater the fluctuation of the RSEDI time series, while the smaller the $\mathrm{CV}$ denotes a more stable state. 


\section{Theil-Sen Median Trend Analysis and the Mann-Kendall Test}

The Theil-Sen Median trend analysis is a nonparametric statistical analysis method, which has higher accuracy than linear regression method and is particularly effective for estimating small series trends [60-61]. It is often used to reveal trends in vegetation [29]. It can be calculated by [62]:

$$
S_{R S E D I}=\operatorname{median}\left(\frac{R S E D I_{j}-R S E D I_{i}}{j-i}\right), i<j
$$

...where $S_{R S E D I}$ is the Theil-Sen Median; RSEDI and $R S E D I$ represent the RSEDI values for the year $j$ and $i$, respectively. This method calculates the median slopes of $\mathrm{n}(\mathrm{n}-1) / 2$ pair-wise combinations. When $S_{R S E D I}>0$, the ecological environment presents an improving trend; otherwise, it displays a degrading trend.

The Mann-Kendall test is a non-parametric statistical test method, which has the advantage that the data does not need to follow a normal distribution and is not disturbed by outliers [63-65]. It is used to measure the significance of trends. Using the statistic $Z$ as the time series index, the calculation is as follows [29]:

$$
Z= \begin{cases}\frac{S-1}{\sqrt{\operatorname{var}(S)}}, & S>0 \\ 0, & S=0 \\ \frac{S-1}{\sqrt{\operatorname{var}(S)}}, & S<0\end{cases}
$$

...where,

$$
\begin{array}{r}
S=\sum_{i=1}^{n-1} \sum_{j=i+1}^{n} \operatorname{sgn}\left(R S E D I_{j}-R S E D I_{i}\right) \\
\operatorname{sgn}\left(R S E D I_{j}-R S E D I_{i}\right)=\left\{\begin{array}{c}
1, R S E D I_{j}-R S E D I_{i}>0 \\
0, R S E D I_{j}-R S E D I_{i}=0 \\
-1, R S E D I_{j}-R S E D I_{i}<0
\end{array}\right.
\end{array}
$$

The variance is computed as:

$$
\operatorname{var}(S)=\frac{n(n-1)(2 n+5)}{18}
$$

...where $R S E D I_{j}$ and $R S E D I_{i}$ have the same meaning as previous (equation 4); sgn is the sign function. Given a significant level $\alpha,|Z|>u_{1-\alpha / 2}$ indicates that the time series shows significant variations on the level of $\alpha$.

\section{Hurst Exponent}

The Hurst exponent $(\mathrm{H})$ has been widespread used in the fields of climatology, economics, geology and hydrology [29], which is an effective method to quantitatively describe the sustainability of time series data. It can be conducted based on rescaled range analysis $(\mathrm{R} / \mathrm{S})$, the procedures are as follows [6667]:
1. To define the difference of time series $\{\xi(t)\}$,

$\xi(t)=R S E D I(t)-R S E D I(t-1), \quad t=1,2, \cdots, n$

...where $R S E D I(t)$ is the pixel value of $R S E D I$ at time $t$.

2 . To define the mean of the time series,

$$
\langle\xi\rangle_{t}=\frac{1}{\tau} \sum_{1}^{\tau} \xi(t), \quad \tau=1,2, \cdots, n
$$

3. To calculate the accumulated deviation,

$$
X(t, \tau)=\sum_{1}^{\tau}\left(\xi(t)-\langle\xi\rangle_{t}\right), \text { where } 1 \leq t \leq \tau
$$

4. To create the range sequence,

$$
R(\tau)=\max _{1 \leq t \leq \tau} X(t, \tau)-\min _{1 \leq t \leq \tau} X(t, \tau)
$$

5. To create the standard deviation sequence,

$$
S(\tau)=\left\{\frac{1}{\tau} \sum_{t=1}^{\tau}\left[\left(\xi(t)-\langle\xi\rangle_{t}\right)\right]^{2}\right\}^{1 / 2}
$$

6. To calculate Hurst exponent

$$
R(\tau) / S(\tau)=(c \tau)^{H}
$$

The value of $\mathrm{H}$ is obtained using the least squares method fitting by the equation:

$$
\log (R / S)_{n}=a+H \times \log (n)
$$

The value of $\mathrm{H}$ ranges from 0 to 1 [68-69]. When $\mathrm{H}$ is equal to 0.5 , it indicates that the RSEDI time series is random and has no sustainability, showing the trend of the time series in the future has nothing to do with that of the research period; when $\mathrm{H}$ is greater than 0.5 , it means that the RSEDI time series is persistent indicating the same trend as the past; and when $\mathrm{H}$ is less than 0.5 , it refers to the anti-persistence of the NDVI time series, representing the opposite trend with the past.

Specific to Hexi oases, based on the sequential RSEDI data, their differences and the $\mathrm{CV}$ value were calculated first. $\mathrm{CV}$ was used to monitor the volatility of the ecological environment changes. And then, the Theil-Sen Median trend analysis combined with the Mann-Kendall test was applied to check the changing trend and its significance ( $\alpha$ was set to 0.05 ). Finally, the $\mathrm{H}$ index was employed to test the ecological sustainability over the past 30 years.

\section{Results}

\section{Variations of the Six Indexes}

Statistical results (Table 3) showed the mean value of the six indicators in each study year. Among them, 
Table 3. Means of the six indexes.

\begin{tabular}{|c|c|c|c|c|c|c|c|c|}
\hline Index & 1986 & 1990 & 1995 & 2000 & 2005 & 2010 & 2015 & 2020 \\
\hline NDVI & 0.227 & 0.224 & 0.255 & 0.247 & 0.272 & 0.270 & 0.298 & 0.283 \\
\hline WI & 0.432 & 0.446 & 0.451 & 0.447 & 0.468 & 0.447 & 0.447 & 0.433 \\
\hline Albedo & 0.447 & 0.433 & 0.476 & 0.450 & 0.554 & 0.470 & 0.399 & 0.418 \\
\hline SI & 0.516 & 0.478 & 0.454 & 0.517 & 0.508 & 0.526 & 0.476 & 0.499 \\
\hline IBI & 0.759 & 0.758 & 0.749 & 0.747 & 0.730 & 0.737 & 0.735 & 0.744 \\
\hline LST & 0.510 & 0.591 & 0.578 & 0.512 & 0.566 & 0.568 & 0.556 & 0.553 \\
\hline
\end{tabular}

the value of NDVI showed a fluctuating upward trend, indicating that the ecological environment of the study area was gradually getting better. The value of WI increased from 1986 to 2005, and decreased from 2005 to 2020. The value of Albedo, which showed a downward trend overall, fluctuated greatly during 1986-2010. It dropped sharply with a decline rate of $15.11 \%$ during $2010-2015$, and it increased slightly with a growth rate of $4.76 \%$ during 2010-2015. Like Albedo, SI also showed a downward trend overall. The value of SI decreased during 1986-1995 and 2000-2015 with a change of $12.02 \%$ and $7.93 \%$, respectively. During $1995-2000$ and $2015-2020$, It increased with a change of $13.88 \%$ and $4.83 \%$, respectively. The value of LST, which showed an upward trend overall, increased by $15.88 \%$ and $10.96 \%$ respectively during $1986-1990$ and $2000-2010$. And it dropped by $13.37 \%$ and $2.66 \%$ respectively during 1990-2000 and 2010-2020. The value of IBI showed a trend of first decreasing and then increasing.

\section{The Temporal Variation Characteristics of RSEDI}

The mean value of RSEDI of Hexi oases fluctuated between 0.38 and 0.43 (Fig. 2), reaching a peak of 0.422 in 2005 . The changes of the mean RSEDI during the study period could be divided in three phases: (1) a rapid increase stage with a growth rate of $9.33 \%$ during the period 1986-2005; (2) a rapid decrease stage

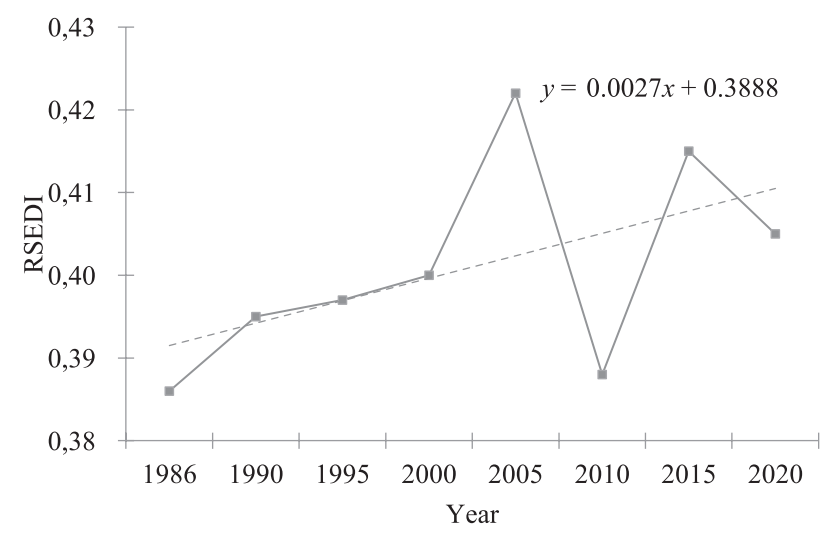

Fig. 2. Changes of RSEDI values in the study years. with a decline rate of $8.06 \%$ during the period 2005 2010; and (3) a fluctuating increase stage with a growth rate of $4.38 \%$ during the period 2010-2020. On the whole, the mean RSEDI showed an increasing trend, increasing from 0.386 in 1986 to 0.405 in 2020, which indicated that the quality of the ecological environment had been improved.

\section{Spatial Distribution Characteristics of RSEDI}

To deeply analyze the ecological environmental status of the study area, RSEDI images were further divided into five levels. Statistical results (Table 4) showed that the ecological environmental status changed significantly during 1986-2000 and 2010-2020, but was relatively stable during 2000-2010. During the period of 1986-1995, the proportion of areas with very poor and poor level in the study area decreased significantly, by $3.70 \%$ and $5.77 \%$ respectively; the proportion of areas with acceptable level decreased first and then increased; and the proportion of areas with good and very good level had been increasing, by $1.39 \%$ and $3.42 \%$ respectively. During the period 1995-2000, the proportion of areas with very poor and poor level increased; the proportion of areas with acceptable level decreased; and the proportion of areas with good and very good level also decreased slightly. During the period of 2000-2010, all levels were relatively stable. During the period of 2010-2020, the proportion of areas with very poor and very good level first decreased and then increased; the proportion of areas with acceptable and good level changed in contrast, increasing first and then decreasing; and the proportion of areas with poor level decreased slightly.

Overall, the quality of the ecological environment in each period of the study area was mainly in poor level, followed by acceptable level, indicating that the ecological environment was poor and fragile, and vulnerable to external environmental interference. The distribution of the quality of the ecological environment gradually tended to be bipolar (good or bad) over time, indicating that while the ecological environment had been improved, it also faced huge challenges.

The spatial heterogeneity of the ecological environment quality was obvious (Fig. 3). The darker 
Table 4. Area ratio of each RSEDI level in the study years (\%).

\begin{tabular}{|c|c|c|c|c|c|c|c|c|}
\hline RSEDI level & 1986 & 1990 & 1995 & 2000 & 2005 & 2010 & 2015 & 2020 \\
\hline 1 (very poor) & 8.76 & 9.44 & 5.06 & 13.26 & 13.40 & 12.58 & 8.78 & 16.13 \\
\hline 2 (poor) & 46.67 & 46.94 & 40.90 & 43.07 & 41.13 & 44.13 & 43.52 & 40.05 \\
\hline 3 (acceptable) & 26.02 & 22.62 & 30.69 & 21.49 & 20.72 & 19.83 & 21.44 & 19.01 \\
\hline 4 (good) & 12.59 & 12.73 & 13.98 & 14.00 & 14.51 & 13.80 & 17.93 & 12.41 \\
\hline 5 (very good) & 5.96 & 8.27 & 9.38 & 8.18 & 10.24 & 9.66 & 8.32 & 12.40 \\
\hline
\end{tabular}

patches representing good or very good level were mainly distributed inside the artificial oases in the central and southern part of the study area, where the ecological environment quality was greatly affected by human beings. The light-colored patches denoting poor or very poor level were concentrated around the artificial oases in the north, closing to the desert. Overall, the color darkening trend indicated that the environment of Hexi oases had been gradually improved during the past 30 years.

Environmental Interannual Change Analysis

Change detection results of the RSEDI images (Table 5) revealed that the greatest changes of improvements occurred in 1990-1995, while the most
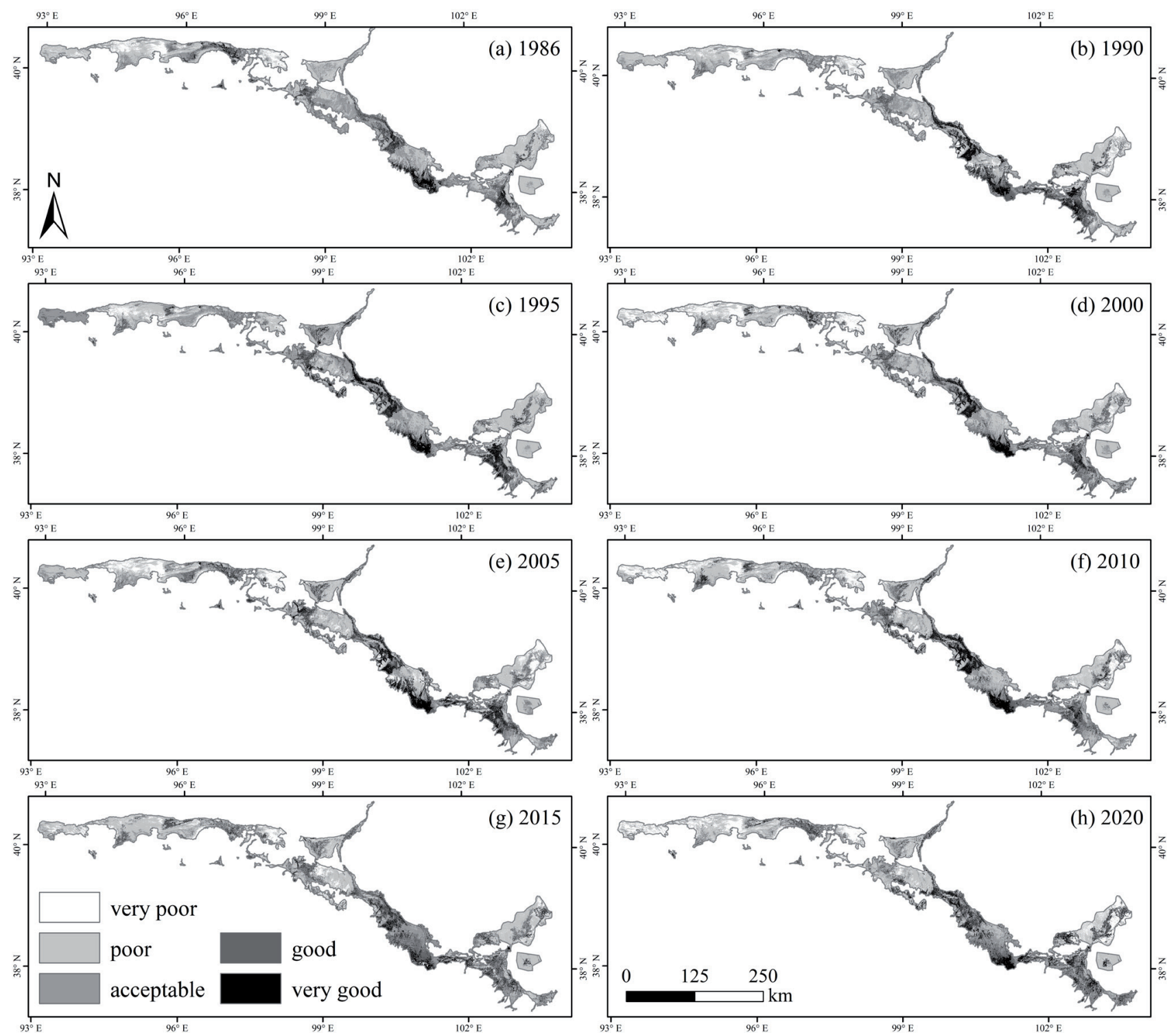

Fig. 3. Spatial distribution of RSEDI in each study year. 
Table 5. Area ratio of environmental change in seven durations (\%).

\begin{tabular}{|c|c|c|c|c|c|c|c|}
\hline & $1986-1990$ & $1990-1995$ & $1995-2000$ & $2000-2005$ & $2005-2010$ & $2010-2015$ & $2015-2020$ \\
\hline Improved & 21.43 & 31.18 & 12.34 & 25.34 & 23.86 & 26.79 & 19.90 \\
\hline Unchanged & 57.98 & 54.75 & 56.47 & 52.27 & 51.05 & 52.64 & 52.06 \\
\hline Degraded & 20.59 & 14.07 & 31.18 & 22.38 & 25.09 & 20.58 & 28.04 \\
\hline
\end{tabular}

remarkable degradation turned up at the interval of 1995-2000. During 1995-2000, 2005-2010, and 20152020, the degrading trend was more evident than improving trend. The situations of environmental changes were on the opposite in 1986-1990, 1990-1995, 2000-2005 and 2010-2015.

Fig. 4 showed the spatial distribution of environmental change in 1986-1990, 1990-1995, 1995 2000, 2000-2005, 2005-2010, 2010-2015 and 20152020. It showed that during the period of 1986-1990, the environment degradation areas were mainly distributed in Guazhou, Sunan, Ganzhou, and the eastern part of Minqin; while the improved areas were mainly distributed in Dunhuang, Jinta, Yongchang, and Liangzhou. During 1995-2000, 2005-2010 and 2015-2020, the environment degradation was relatively severe, most of which were distributed on the edge of the oases in the north. In the other durations, the condition was greatly improved. Among them, it was the most obvious during the period of 1990-1995, followed by 2010-2015.

\section{The Change Intensity of the Ecological Environment}

The spatial distribution of coefficient of variation of RSEDI (Fig. 5) reflected the spatial stability of the ecological environment. The high coefficients of variation denoting drastic changes in the ecological environment were mainly distributed on the periphery of the oasis, closing to the desert, mainly in Dunhuang, Yumen, and Minqin. The ecological environment in these areas was fragile and vulnerable to external environmental interference. The low coefficients of variation representing the stability of the ecological environment were distributed throughout the study area, mainly in the oasis areas of the central and western regions such as Jiayuguan, Linze, and Ganzhou. These areas were mainly affected by human factors. On the whole, the ecological environment changes of the Hexi oases were relatively stable, and the areas with low coefficients of variation (less than 0.3) accounted for $62.70 \%$, which were considerably greater than those with high coefficients of variation (more than 0.5 , accounting for $9.79 \%$ ).

\section{Changing Trends of the Ecological Environment}

By integrating the results of the Theil-Sen median trend analysis and the Mann-Kendall test, the trends of the ecological environment were divided into five types according to the real conditions of the study area (Table 6). Fig. 6 reflected the spatial distribution of the trends of RSEDI change of Hexi oases from 19862015. The darker patches representing ecologicallyimproved were mostly distributed in Ganzhou, Shandan and Yongcahng. The light-colored patches denoting ecologically-declined mainly occurred in Dunhuang, Guazhou, and Sunan. During the study period, in most areas of the Hexi oases, the ecological environment had no change, accounting for $42.62 \%$. The ecological improvement areas $(26.53 \%)$ were smaller than the ecological decline areas $(30.83 \%)$, indicating that the ecological environment of the Hexi oases had been improved, but it also suffered severe damages.

\section{The Sustainability of Ecological Environment Variations}

The Hurst exponent of the RSEDI in Hexi oases is 0.59 on average (Fig. 7). Areas with a Hurst

Table 6 . Trends of RSEDI change in the study area.

\begin{tabular}{|c|c|c|c|}
\hline $\mathrm{S}_{\text {RSEDI }}$ & $\mathrm{Z}$ & RSEDI trend & Area percentage (\%) \\
\hline$>0.01$ & $>1.96$ & Significant improvement & 12.67 \\
\hline$>0.01$ & $-1.96 \sim 1.96$ & Slight improvement & 13.86 \\
\hline$<-0.01$ & $-1.96 \sim 1.96$ & Slight degradation & 10.24 \\
\hline$<-0.01$ & $<-1.96$ & Severe degradation & 20.59 \\
\hline$-0.01 \sim 0.01$ & - & Stable & 42.62 \\
\hline
\end{tabular}

Note: - represents all the $\mathrm{Z}$ values. 


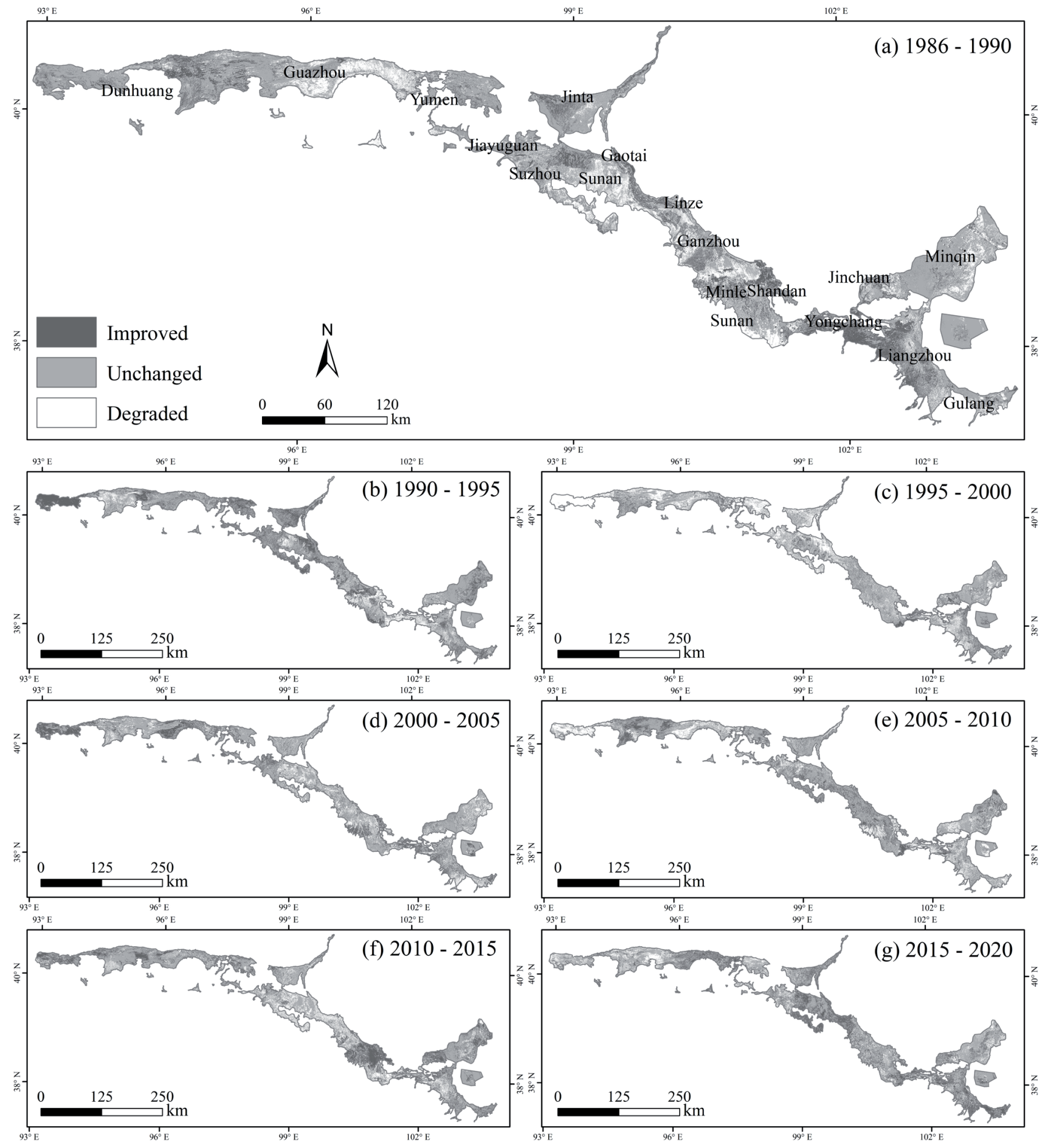

Fig. 4. Environmental change of RSEDI in seven durations.

exponent greater than 0.5 were persistent, accounting for $75.14 \%$ of the study area; those less than 0.5 were anti-persistent accounting for $24.86 \%$. In short, the persistence of the ecological environment changes of the Hexi oases is far stronger than the anti-persistence. To reveal the changing trends and sustainability of the ecological environment in the study area, the results of the Theil-Sen median trend analysis and Mann-Kendall test were superimposed with the Hurst index results, and the results were divided into six classes (Table 7).
Because the areas of anti-persistence were small, they were uniformly divided into anti-persistence changes, including anti-persistence and significant improvement, anti-persistence and slight improvement, antipersistence and slight degradation, and anti-persistence and severe degradation.

Fig. 8 showed the spatial distribution of coupling results of RSEDI change trends and Hurst exponent of the Hexi oases. As suggested by Fig. 8 and Table 7, the ecological environment of the Hexi oases is mostly 


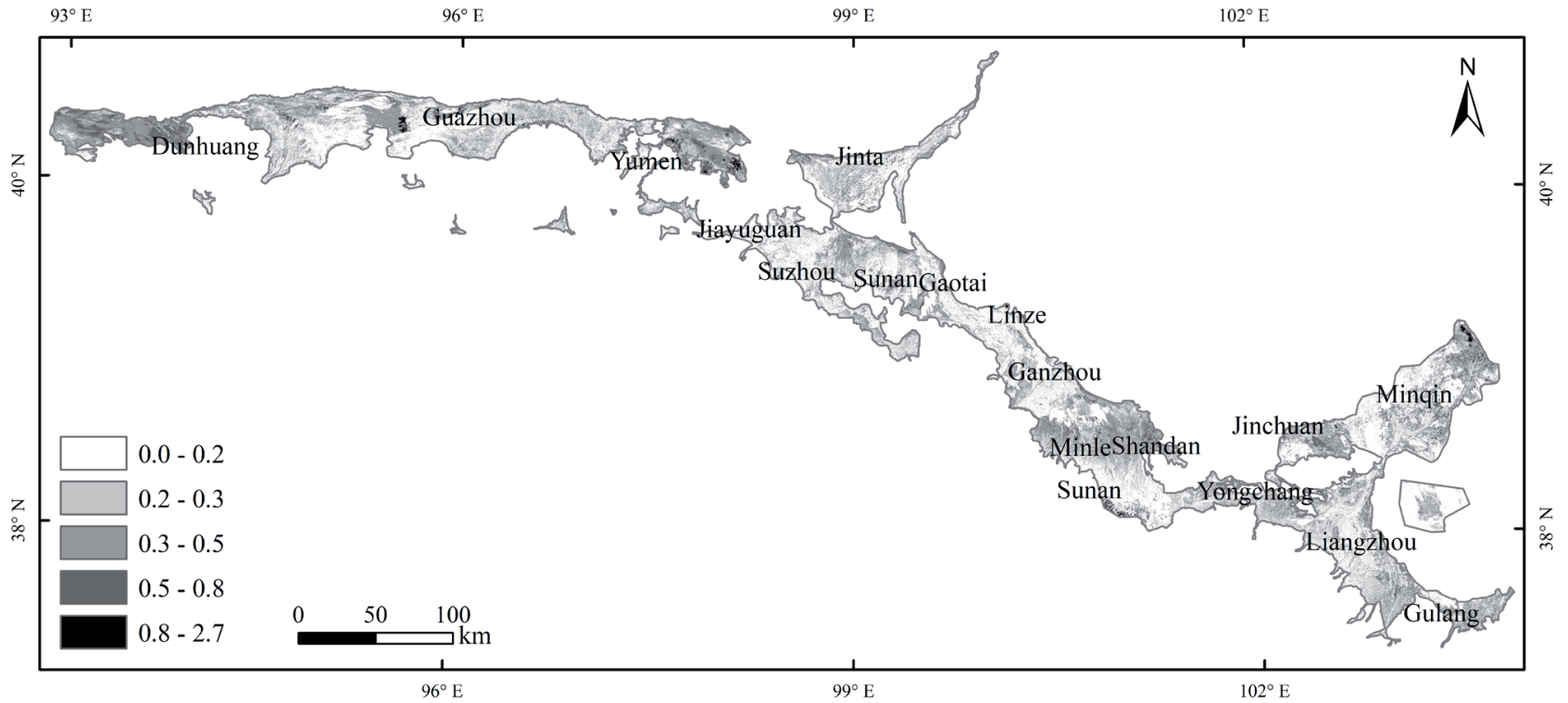

Fig. 5. Spatial distribution of coefficient of variation of RSEDI.

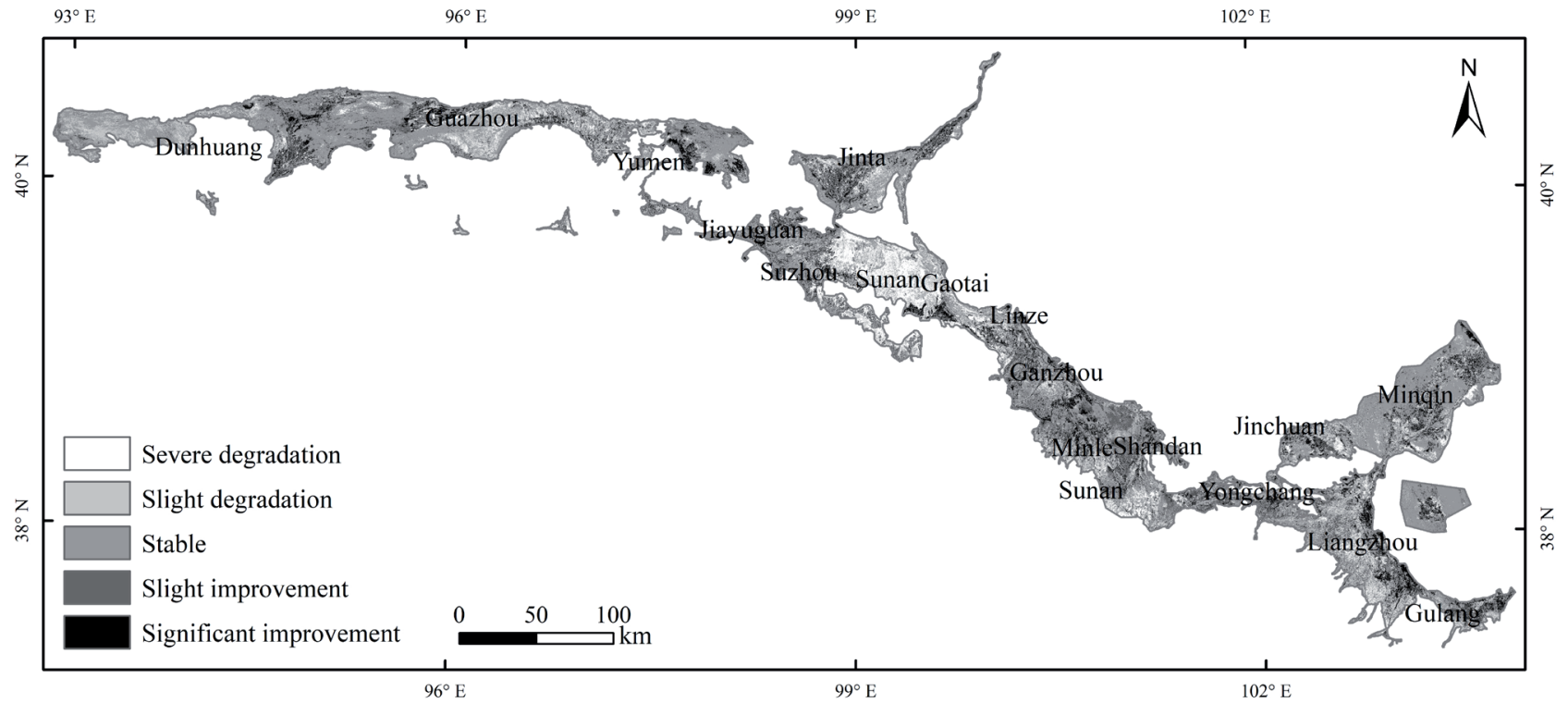

Fig. 6. Trends of RSEDI change from 1986-2020.

Table 7. Trends of RSEDI change in the study area.

\begin{tabular}{|c|c|c|c|c|}
\hline $\mathrm{H}$ & $\mathrm{S}_{\mathrm{RSEDI}}$ & $\mathrm{Z}$ & RSEDI trend & Area percentage (\%) \\
\hline$>0.5$ & $>0.01$ & $>1.96$ & Persistence and significant improvement & 9.85 \\
\hline$>0.5$ & $>0.01$ & $-1.96 \sim 1.96$ & Persistence and slight improvement & 10.87 \\
\hline$>0.5$ & $<-0.01$ & $-1.96 \sim 1.96$ & Persistence and slight degradation & 6.86 \\
\hline$>0.5$ & $<-0.01$ & $<-1.96$ & Persistence and severe degradation & 14.68 \\
\hline$<0.5$ & - & - & Anti-persistence & 15.12 \\
\hline- & $-0.01 \sim 0.01$ & - & Stable & 42.62 \\
\hline
\end{tabular}

Note: - represents all the corresponding values $\left(\mathrm{H}, \mathrm{S}_{\mathrm{RSEDI}}\right.$ or $\left.\mathrm{Z}\right)$. 


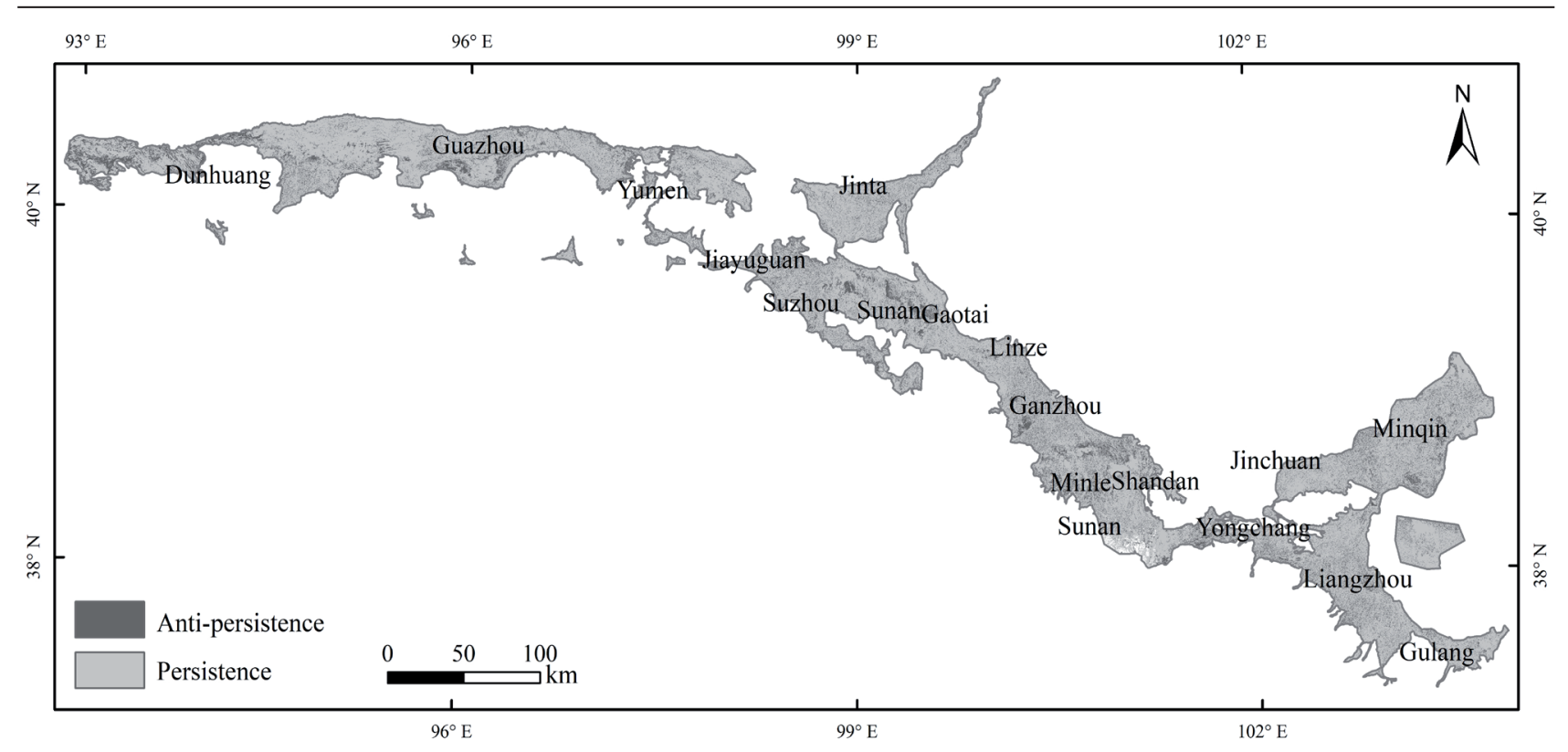

Fig. 7. Sustainability of RSEDI Change in Hexi oases from 1986 to 2020.

in a stable state, accounting for $42.62 \%$. The lightcolored patches showing persistence and significant/ slight improvement accounted for $20.72 \%$, which were distributed throughout the study area, mostly around the periphery of artificial oasis such as Shandan, and Yongchang. The darker patches representing persistence and severe/slight degradation accounted for $21.55 \%$, which were concentrated in the middle of the study area, mainly in Sunan, and Gaotai. The blackish patches denoting anti-persistence accounted for only $15.12 \%$, mainly distributed in Dunhuang, and the interiors of some artificial oasis such as Sunan, and Gaotai.

\section{Discussion}

With the rapid development of the social economy, the artificial oases are expanding rapidly, and the Hexi oases are facing the dual pressure of economic growth and ecological restoration [12, 70-71]. This study has demonstrated that the ecological environment of the study area is mainly in poor level. Although it has gradually improved during the past 30 years, it also faces huge challenges. It is consistent with the results reported by Wei et al. [33], Gong et al. [72] and Fu et al. [73].

As a typical ecologically fragile area, Hexi oases have a poor ecological foundation and are easily affected by human activities. Under the influence of policies and regulations, human production and lifestyles are constantly changing and affect the ecological environment of oases. The "Immigration Policy" conducted in 1983 has promoted immigration from Dingxi to the Hexi Corridor; from the mid-1980s to the early 1990s, under the influence of the "market economy", irrigation, fertilization, management and other technologies continue to develop, and large areas of wasteland and grassland are reclaimed into cultivated land, and the oases ecological environment has been improved. In the middle and late 1990s, the Shule River Basin has launched the "Comprehensive Development Project for Agricultural Irrigation and Resettlement". The immigration has rapidly increased the population of Yumen and Guazhou counties, the area of oasis irrigation and the number of electromechanical wells, and eventually intensified the expansion of oasis and caused environmental issues. After 2000, the implementation of the policies of "returning farmland to forest, returning grazing land to grass" and "water diversion" is conducive to the overall stability of the oases, and the ecological environment has been gradually improved. In 2001, the implementation of the "Jingdian Phase II Project" has alleviated the water resource crisis and the rapid deterioration of the ecological environment in Minqin County to a certain extent. In 2007, the "Comprehensive Treatment Program of the Shiyang River Basin" has been implemented to prevent the continuous deterioration of Minqin's ecology, which primarily involves shutting wells and pressing fields, adjusting industrial structure, water-saving transformation of irrigation districts and ecological migration [974]. The implementation of ecological protection policies and projects has greatly promoted the improvements of the ecological environment, while the over-development of oases also has a negative impact on the ecological environment [75].

In addition, natural factors such as temperature and precipitation also affect the ecological environmental changes. Studies have shown that in the past 30 years, the temperature in the Hexi region has generally shown an upward trend, and its central part is the area with the largest increase in temperature and is most sensitive to climate change [76]. Precipitation shows a clear upward 
trend, and evaporation also shows an increasing trend [77]. The relative humidity increases first and then decreases, which is consistent with the change trend of WI in this paper. Relative humidity changes in the western region are relatively small, and changes in the eastern and central regions are relatively large [76].

The quality and time of remote sensing image data will affect the evaluation results to a certain extent, and the formation and development of regional ecosystems are affected by various factors such as human factors and natural conditions. In future research, we should comprehensively consider various aspects of ecological impact factors for analysis, and further explore comprehensive multi-factor evaluation methods.
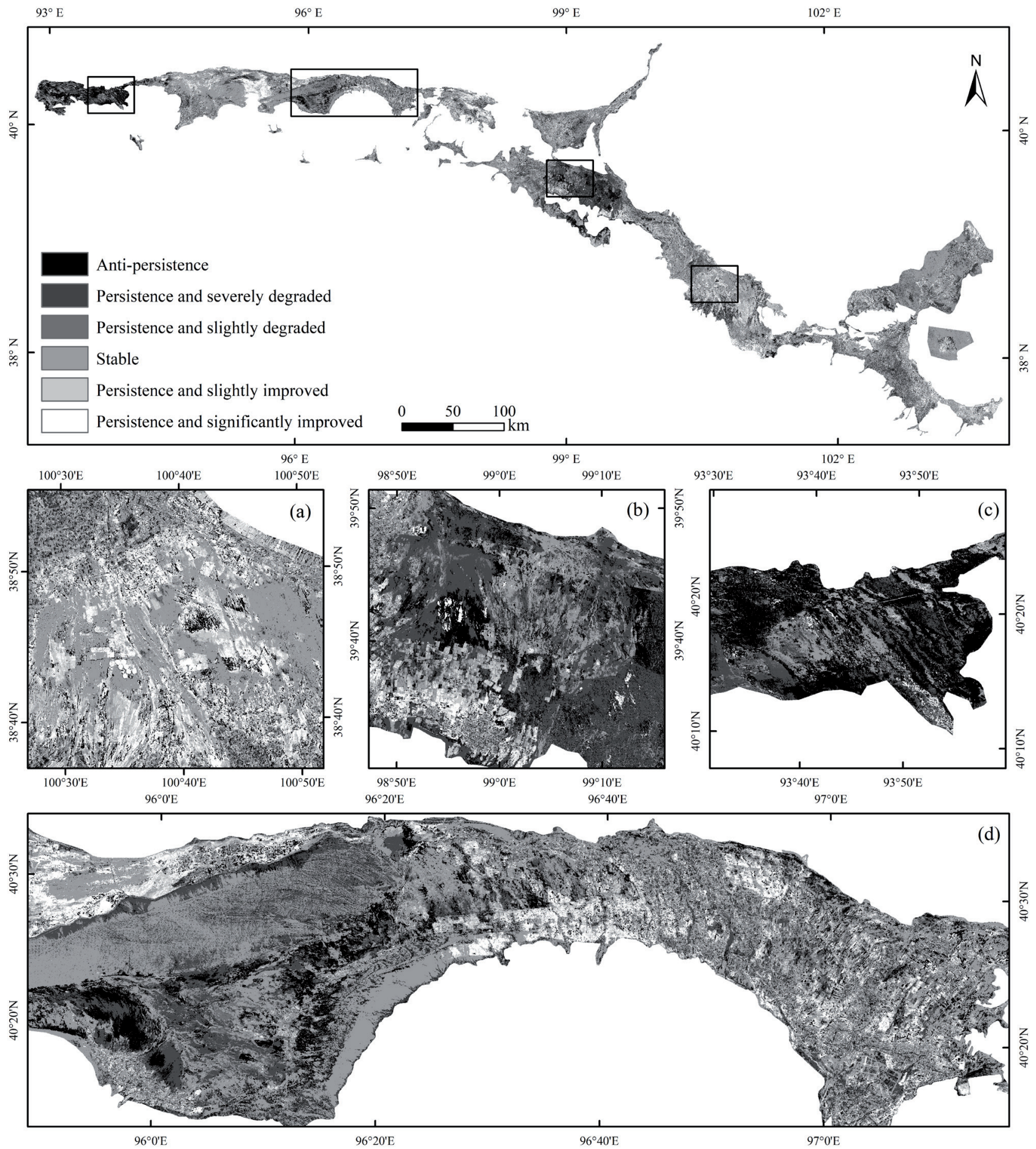

Fig. 8. Spatial distribution of coupling results of RSEDI change trends and Hurst exponent in Hexi oases. a) represents the areas with persistence and significant/slight improvement, and stable; b) represents the areas with persistence and severe/slight degradation; c) represents the areas with anti-persistence; and d) represents the areas with complicated changes, and multiple modes of change coexist. 


\section{Conclusions}

We generated time series of the ecological status images of the Hexi oases from 1986-2020 based on Landsat TM/OLI images and several typical indices, and quantitatively analyzed the changes of the ecological environment quality by integrating multiple analysis methods.

There are four main conclusions in this paper. Firstly, the mean value of RSEDI of Hexi oases showed an increasing trend, increasing from 0.386 in 1986 to 0.405 in 2020. Secondly, the ecological environment changes of the Hexi oases were relatively stable, areas with low coefficients of variation accounted for $62.70 \%$. Thirdly, the ecological improvement areas (26.53\%) were smaller than the ecological decline areas (30.83\%), and areas with no change accounted for $42.62 \%$. Finally, $75.14 \%$ of areas were persistent, showing the ecological environment changes had strong sustainability. The areas with persistence and improvement accounted for $20.72 \%$, which were distributed throughout the study area, mostly around the periphery of artificial oasis such as Shandan, and Yongchang. The areas with persistence and degradation accounted for $21.55 \%$, which were concentrated in the middle of the study area, mainly in Sunan and Gaotai.

\section{Acknowledgements}

This research was funded by the National Key Research and Development Program of China [NO.2018YFA0606404-03], the Strategic Priority Research Program of Chinese Academy of Sciences [NO. XDA2009000001], the Science and Technology Basic Resource Investigation Program of China [NO. 2017FY101003], and the Fundamental Research Funds for the Central Universities [NO. lzujbky-2019-it27, lzujbky-2020-71].

\section{Conflict of Interest}

The authors declare no conflict of interest.

\section{References}

1. REYNOLDS J.F., SMITH D.M.S., LAMBIN E.F., TURNER B.L., MORTIMORE M., BATTERBURY S.P.J., DOWNING T.E., DOWLATABADI H., FERNÁNDEZ R.J., HERRICK J.E., HUBER-SANNWALD E., JIANG H., LEEMANS R., LYNAM T., MAESTRE F.Y., AYARZA M., WALKER B. Global desertification: building a science for dryland development. Science (New York, N.Y.), 316 (5826), 847, 2007.

2. MCDONNELL M.J., MACGREGOR-FORS I. The ecological future of cities. Science, 352 (6288), 936, 2016.

3. WILLIAMS M., LONGSTAFF B., BUCHANAN C., LLANSO R., DENNISON W. Development and evaluation of a spatially-explicit index of Chesapeake Bay health. Marine Pollution Bulletin, 59 (1-3), 14, 2009.

4. XIE Y.W., ZHAO H., WANG G.S. Spatio-Temporal Changes in Oases in the Heihe River Basin of China: 1963-2013. Écoscience, 22, 33, 2015.

5. XIE Y.W., BIE Q., LU H., HE L. Spatio-Temporal Changes of Oases in the Hexi Corridor over the Past 30 Years. Sustainability, 10 (12), 4489, 2018.

6. LI W.D., LI Z.Z., WANG J.Q. Evaluation of oasis ecosystem risk by reliability theory in an arid area: A case study in the Shiyang River basin, China. Journal of Environmental Sciences, 19 (4), 508, 2007.

7. MENG X.J., ZHANG S.F., ZHANG Y.Y., WANG C.C. Temporal and spatial changes of temperature and precipitation in Hexi Corridor during 1955-2011. Journal of Geographical Sciences, 23 (4), 653, 2013.

8. ZHAO J., ZHOU Y.Z., DENG X.Y. Temporal-spatial Dynamic Change Characteristics of Vegetation Coverage in Arid Regions of Northwest China. Forest Resources Management, 1, 118, 2017 [In Chinese].

9. HAO Y.Y., XIE Y.W., MA J.H., ZHANG W.P. The critical role of local policy effects in arid watershed groundwater resources sustainability: A case study in the Minqin oasis, China. Science of The Total Environment, 601-602, 1084, 2017.

10. ZHANG X.X., XIE Y.W. Detecting Historical Vegetation Changes in the Dunhuang Oasis Protected Area Using Landsat Images. Sustainability, 9, 1780, 2017.

11. ZHANG F., TIYIP T., DING J.L., SAWUT M., JOHNSON V.C., TASHPOLAT N., GUI D.W. Vegetation fractional coverage change in a typical oasis region in Tarim River Watershed based on remote sensing. Journal of Arid Land, 5, 89, 2013.

12. KING C., THOMAS D.S.G. Monitoring environmental change and degradation in the irrigated oases of the Northern Sahara. Journal of Arid Environments, 103, 36, 2014.

13. KENNEDY R.E., ANDRÉFOUËT S., COHEN W.B., GÓMEZ C., GRIFFITHS P., HAIS M., HEALEY S.P., HELMER E.H., HOSTERT P., LYONS M.B. Bringing an ecological view of change to Landsat-based remote sensing. Frontiers in Ecology and the Environment, 12 (6), 339, 2014.

14. QIU B.W., CHEN G., TANG Z.H., LU D.F., WANG Z.Z., CHEN C. Assessing the Three-North Shelter Forest Program in China by a novel framework for characterizing vegetation changes. ISPRS Journal of Photogrammetry and Remote Sensing, 133, 75, 2017.

15. DE ARAUJO BARBOSA C.C., ATKINSON P.M., Dearing J.A. Remote sensing of ecosystem services: A systematic review. Ecological Indicators, 52, 430, 2015.

16. YANG Y.J., ERSKINE P.D., LECHNER A.M., MULLIGAN D., ZHANG S.L., WANG Z.Y. Detecting the dynamics of vegetation disturbance and recovery in surface mining area via Landsat imagery and Land Trendr algorithm. Journal of Cleaner Production, 178, 353, 2018.

17. MARTÍNEZ B., GILABERT M.A. Vegetation dynamics from NDVI time series analysis using the wavelet transform. Remote Sensing of Environment, 113 (9), 1823, 2009.

18. XU H.Q., WANG Y.F., GUAN H.D., SHI T.T., HU X.S. Detecting Ecological Changes with a Remote Sensing Based Ecological Index (RSEI) Produced Time Series and Change Vector Analysis. Remote Sensing, 11, 2345, 2019.

19. HOAN N T., QUYNH H.T., HANG L.M., HA N.M., NGOC H.T.H, PHONG D.X. Estimation of Land Use Changes 
in Tan Rai Bauxite Mine by Multi-Variants Change Vector Analysis (MCVA) on Multi-Temporal Remote Sensing Data. Journal of Geoscience and Environment Protection, 8 (3), 70, 2020.

20. FENSHOLT R., PROUD S.R. Evaluation of Earth Observation based global long term vegetation trends Comparing GIMMS and MODIS global NDVI time series. Remote Sensing of Environment, 119, 131, 2012.

21. ATTA-UR-RAHMAN, DAWOOD M. Spatio-statistical analysis of temperature fluctuation using Mann-Kendall and Sen's slope approach. Climate Dynamics, 48, 783, 2017.

22. JIANG W.G., YUAN L.H., WANG W.J., CAO R., ZHANG Y.F., SHEN W.M. Spatio-temporal analysis of vegetation variation in the Yellow River Basin. Ecological Indicators, 51, 117, 2015.

23. SULLIVAN C.A., SKEFFINGTON M.S., GORMALLY M.J., FINN J.A. The ecological status of grasslands on lowland farmlands in western Ireland and implications for grassland classification and nature value evaluation. Biological Conservation, 143 (6), 1529, 2010.

24. FITOKA E., TOMPOULIDOU M., HATZIIORDANOU L., APOSTOLAKIS A., HÖFER R., WEISE K., VERVERIS C. Water-related ecosystems' mapping and assessment based on remote sensing techniques and geospatial analysis: The SWOS national service case of the Greek Ramsar sites and their catchments. Remote Sensing of Environment, 245, 111795, 2020.

25. COUTTS A.M., HARRIS R.J., PHAN T., LIVESLEY S.J., WILLIAMS N.S.G., TAPPER N.J. Thermal infrared remote sensing of urban heat: hotspots, vegetation, and an assessment of techniques for use in urban planning. Remote Sensing of Environment, 186, 637, 2016.

26. XU H.Q. A remote sensing urban ecological index and its application. Acta Ecologica Sinica, 33 (24), 7853, 2013 [In Chinese].

27. RHEE J., IM J., CARBONE G.J. Monitoring agricultural drought for arid and humid regions using multi-sensor remote sensing data. Remote Sensing of Environment, 114 (12), 2875, 2010.

28. ALEJANDRA M.M., ALBERTO B.D., MARINO S.R.L. Urban environmental quality assessment using remote sensing and census data. International Journal of Applied Earth Observation and Geoinformation, 71, 95, 2018.

29. LI J.L., JIANG D.W., LI N., HAN X.R., QIN X.Z., TANG G.T. Application of multi-source thematic data on ecoenvironment status evaluation in national key counties with ecological functions. Environmental Monitoring in China, 34 (5), 75, 2018 [In Chinese].

30. HUANG S., FENG Q., LU Z.X., WEN X.H., DEO R.C. Trend analysis of water poverty index for assessment of water stress and water management polices: a case study in the Hexi Corridor, China. Sustainability, 9, 756, 2017.

31. ZHANG Z.C., DONG Z.B., LI J.Y., QIAN G.Q., JIANG C.W. Implications of surface properties for dust emission from gravel deserts (gobis) in the Hexi Corridor. Geoderma, 268, 69, 2016.

32. WEI J.J. The Hexi Area Oasis Extraction Method and Spatial Distribution Based on Remote Sensing. Lanzhou University, Lanzhou, China, 2016 [In Chinese].

33. WEI W., GUO Z.C., XIE B.B., ZHOU J.J., LI C.H. Spatiotemporal evolution of environment based on integrated remote sensing indexes in arid inland river basin in northwest china. Environmental Science \& Pollution Research International, 26 (13), 13062, 2019.
34. MISHRA N.B., CREWS K.A., THORALF N.M., KENNETH R.Y. MODIS derived vegetation greenness trends in African Savanna: Deconstructing and localizing the role of changing moisture availability, fire regime and anthropogenic impact. Remote Sensing of Environment, 169, 192, 2015

35. SUN Z.D., CHANG N.B., OPP C. Using SPOT-VGT NDVI as a successive ecological indicator for understanding the environmental implications in the Tarim River basin, China. Journal of Applied Remote Sensing, 4, 844, 2010.

36. CRIST E.P. A TM tasseled cap equivalent transformation for reflectance factor data. Remote Sensing of Environment, 17, 301, 1985.

37. HUANG C., WYLIE B., YANG L., HOMER C., ZYLSTRA G. Derivation of a tasselled cap transformation based on Landsat 7 at-satellite reflectance. International Journal of Remote Sensing, 23, 1741, 2002.

38. TODD S.W., HOFFER R.M. Responses of Spectral Indices to Variations in Vegetation Cover and Soil Background. Photogrammetric Engineering and Remote Sensing, 64 (9), 915, 1998.

39. WANNG Q., SHI J.A., CHEN G.J., XUE L.H. Environmental effects induced by human activities in arid Shiyang River basin, Gansu province, northwest China. Environmental Geology, 43, 219, 2002.

40. MAMATSAWUT, TASHPOLAT T., DING J.L., ZHANG F. A GIS-based assessment on sensitivity of soil salinization in arid areas: a case study of the Ugan-Kuqa River Delta. Resources Science, 34 (2), 353, 2012 [In Chinese].

41. LI J.G., PU L.J., ZHU M., ZHANG R.S. The Present Situation and Hot Issues in the Salt-affected Soil Research. Acta Geographica Sinica, 67 (9), 86, 2012 [In Chinese].

42. Weng Y.L., Gong P. A Review on Remote Sensing Technique for Salt-Affected Soils. Scientia Geographica Sinica, 26 (3), 369, 2006 [In Chinese].

43. ZENG Y.N., XIANG N.P., FENG Z.D., HUO H.U. AlbedoNDVI space and remote sensing synthesis index models for desertification monitoring. Scientia Geographica Sinica, 26 (1), 75, 2006 [In Chinese].

44. KHAN N.M., SATO Y. Monitoring hydro-salinity status and its impact in irrigated semi-arid areas using IRS-1B LISS-II data. Asian Journal of Geoinformatics, 1 (3), 63, 2001.

45. ZHAO S.Q., DA L.J., TANG Z.Y., FANG H.J., SONG K., FANG J.Y. Ecological consequences of rapid urban expansion: Shanghai, China. Frontiers in Ecology and the Environment, 4 (7), 341, 2006.

46. XU H.Q. A new index for delineating built-up land features in satellite imagery. International Journal of Remote Sensing, 29 (14), 4269, 2008.

47. WENG Q., FU P., GAO F. Generating daily land surface temperature at Landsat resolution by fusing Landsat and MODIS data. Remote Sensing of Environment, 145, 55, 2014.

48. XU H.Q. Dynamic of soil exposure intensity and its effect on thermal environment change. International Journal of Climatology, 34, 902, 2014.

49. CHANDER G., MARKHAM B.L., HELDER D.L. Summary of current radiometric calibration coefficients for Landsat MSS, TM, ETM+, and EO-1 ALI sensors. Remote Sensing of Environment, 113, 893, 2009.

50. SOBRINO J.A., JIMÉNEZ-MUÑOZ J.C., PAOLINI L. Land surface temperature retrieval from LANDSAT TM 5. Remote Sensing of Environment, 90, 434, 2004. 
51. WENG Q.H., LU D.S., SCHUBRING J. Estimation of land surface temperature-vegetation abundance relationship for urban heat island studies. Remote Sensing of Environment, 89, 467, 2004.

52. ESTOQUE R.C., MURAYAMA Y.J., MYINT S.W. Effects of landscape composition and pattern on land surface temperature: an urban heat island study in the megacities of Southeast Asia. Science of The Total Environment, 577, 349, 2017.

53. QIN Z.H., LI W.J., XU B., CHEN Z.X., LIU J. The estimation of land surface emissivity for Landsat TM6. Remote Sensing for Land \& Resources, 61 (3), 28, 2004 [In Chinese].

54. SHI S.E., WEI W., YANG D., HU X., ZHOU J.J., ZHANG Q. Spatial and temporal evolution of eco-environmental quality in the oasis of SRB based on RSEDI. Chinese Journal of Ecology, 37 (4), 1152, 2018 [In Chinese].

55. ZHANG J. The impact of the oasis development on ecological environment - take Guazhou-Dunhuang Basin as an example. Lanzhou University, Lanzhou, China, 2016 [In Chinese].

56. ZHU Z. Change detection using Landsat time series: A review of frequencies, preprocessing, algorithms, and applications. ISPRS Journal of Photogrammetry and Remote Sensing, 130, 370, 2017.

57. MILICH L., WEISS E. GAC NDVI interannual coefficient of variation $(\mathrm{CoV})$ images: ground truth sampling of the Sahel along north-south transects. International Journal of Remote Sensing, 21, 235, 2000.

58. TUCKER C.J., NEWCOMB W.W., LOS S.O., PRINCE S.D. Mean and inter-year variation of growing-season normalized difference vegetation index for the Sahel 19811989. International Journal of Remote Sensing, 12, 1133, 1991.

59. OINDO B.O., SKIDMORE A.K. Interannual variability of NDVI and species richness in Kenya. International Journal of Remote Sensing, 23, 285, 2002.

60. HOAGLIN D.C., MOSTELLER F., TUKEY J.W. Understanding robust and exploratory data analysis. Wiley-Interscience, New York, US, 2000.

61. SEN P.K. Estimates of the regression coefficient based on Kendall's tau. Journal of the American Statistical Association, 63, 1379, 1968.

62. GOCIC M., TRAJKOVIC S. Analysis of changes in meteorological variables using Mann-Kendall and Sen's slope estimator statistical tests in Serbia. Global and Planetary Change, 100, 172, 2013.

63. KENDALL M.G. Rank Correlation Methods. $4^{\text {th }}$ Edition, Charles Griffin, London, UK, 1975.

64. MANN H.B. Nonparametric tests against trend. Econometrica, 13, 245, 1945.
65. TOSIC I. Spatial and temporal variability of winter and summer precipitation over Serbia and Montenegro. Theoretical and Applied Climatology, 77, 47, 2004.

66. CHEN Y.G. Mathematical methods for geography: foundations and applications. Science Press: Beijing, China, 2011 [In Chinese].

67. SÁNCHEZ GRANERO M.A., TRINIDAD SEGOVIA J.E., GARCÍAPÉREZ J. Some comments on Hurst exponent and the long memory processes on capital markets. Physica A: Statistical Mechanics and its Applications, 387 (22), 5543, 2008.

68. HURST H.E. Long term storage capacity of reservoirs. Transaction of the American Society of Civil Engineer, 116, 770, 1951.

69. MANDELBROT B.B., WALLIS J.R. Robustness of the rescaled range $\mathrm{R} / \mathrm{S}$ in the measurement of noncyclic longrun statistical dependence. Water Resources Research, 5, 967, 1969

70. LUO G.P., LU L., YIN C.Y., FENG Y.X. An analysis of oasis stability in arid areas: a case study in the northern slope areas of Tianshan Mountains. Journal of Arid Land, 1, 49, 2009

71. ZUO L.J., ZHANG Z.X., ZHAO X.L., WANG X., WU W.B., YI L., LIU F. Multitemporal analysis of cropland transition in a climate-sensitive area: A case study of the arid and semiarid region of northwest China. Regional Environmental Change, 14, 75, 2014.

72. GONG J., QIAN C.Y., QIAN D.Y. Land use change and response of environment in the middle-lower reaches of the Shule River Basin during the period of 1977-2013. Arid Zone Research 34 (4), 775, 2017 [In Chinese].

73. FU Y.X., ZHANG J.L., CHEN Y., ZHANG R.Z. LUCC and its environmental effects on the typical oases in the middle reaches of Heihe river basin: Case of Linze and Gaotai oases in Ganzhou. Journal of Arid Land Resources and Environment, 28 (10), 104, 2014 [In Chinese].

74. XUE X., LIAO J., HSING Y., HUANG C., LIU F. Policies, land use, and water resource management in an arid oasis ecosystem. Environmental Management, 55, 1036, 2015.

75. WEI W., XIE Y.W., SHI P.J., ZHOU J.J., LI C.H. Spatial temporal analysis of land use change in the SRB in arid China, 1986-2015. Polish Journal of Environmental Studies, 26 (4), 1789, 2017.

76. HOU Q., ZHANG B., HE H., LI S. Effects of Climate Change on Characteristics of Dry-hot Wind in Hexi Region of Gansu Province. Plateau Meteorology, 39 (1), 162, 2020 [In Chinese].

77. LAI L. Temporal and Spatial Variation Characteristics and Response of Meteorological-Agricultural Drought in the GanSu Province. Northwest A\&F University, Yangling, China, 2020 [In Chinese]. 